Article

\title{
Serum levels of oxidants and protein S100B were associated in the first- episode drug naïve patients with schizophrenia
}

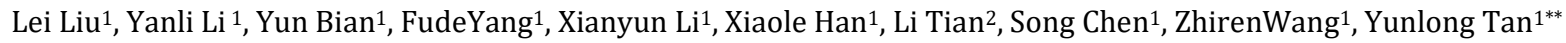 \\ ${ }^{1}$ Center for Biological Psychiatry, Beijing Huilongguan Hospital \& Peking University Huilongguan Clinical Medical School, \\ Changping District, Beijing, China \\ 2University of Helsinki, Neuroscience Center, Helsinki, Finland
}

Received January 29, 2019; Accepted May 20, 2019

\begin{abstract}
Background: Patients with schizophrenia have been noted with an elevation of serum S100B protein concentration, but the pathological process is not known. This study was to investigate the relationship between levels of S100B protein and oxidative stress.

Methods: General information and blood sample were collected from the first-episode drug naïve or drug-free acute stage of patients who met the Diagnostic and Statistical Manual of Mental Disorders-IV (DSM-IV) criteria for schizophrenia and healthy controls. The serum levels of S100B, total oxidants (TOS) and malonaldehyde (MDA) were used to measure the level of oxidative stress in both patients and healthy controls. General linear regression analysis was performed to examine the association of S100B protein with the levels of oxidative stress.

Results: The levels of serum protein S100B were associated with the concentration of both TOS (Beta=15.77; $p=0.0038$ ) and MDA (Beta=7.90; $p=0.0068)$ in the first-episode drug-naive patients $(n=29)$. While both associations were no longer significant in the drug-free acute phase patients $(\mathrm{n}=29)(p>0.05)$, the levels of serum S100B was still consistently associated with TOS (Beta=12.42; $p=0.0026)$ and $\operatorname{MDA}(B e t a=4.11 ; p=0.0480)$ in the combined group of patients group(n=58). Simultaneous analysis of both oxidative markers, we still found that both TOS (Beta=12.88; $p=0.0103$ ) and MDA (Beta=6.46; $p=0.0167$ ) were associated with the serum level of protein S100B in the first-episode drug-naive patients, but not drug-free acute phase patients.
\end{abstract}

Conclusion: Our results suggest that astrocyte activity, serum levels of oxidants, and their cross-talking might be involved in the pathogenesis of schizophrenia. This warrants a further study for understanding the underlying mechanism.

\section{KEYWORDS}

Oxidative stress, S100B protein, schizophrenia, MDA, total oxidants

\section{INTRODUCTION}

Extensive evidence suggests that astrocytes play a crucial role in the central nervous system functions, which have been implicated in the dynamic regulation of neuron energy metabolism and production, synaptic network formation, neuron electrical activity, neurotransmitter release, and immune responses. S100B is a protein of the calcium-binding protein family that is localized in the cytoplasm and nucleus of cells and involved in the regulation of multiple cellular processes including cell cycle progression and differentiation. The protein S100B is glialspecific and secreted by astrocytes; it may function in neurite extension, the proliferation of melanoma cells, stimulation of $\mathrm{Ca}^{2+}$ fluxes, inhibition of protein kinase $\mathrm{C}$ (PKC)-mediated phosphorylation, astrocytosis, and axonal proliferation, and inhibition of microtubule assembly. S100B acts as a neurotrophic factor and neuronal survival protein in the developing central nervous system(CNS)(1); whereas it can spill from the injured cells and enter the extracellular space or bloodstream, and then cause an increase in the serum levels of protein S100B during the acute phase of brain damage.

While the protein S100B is considered a potential clinical marker for blood-brain barrier (BBB) permeability, CNS injury or presence of neurological conditions (2), evidence has also supported that protein S100B may play a role of immune pathology in the etiopathogenesis of schizophrenia(3), which has been believed involving brain-derived neurotrophic factor (BDNF) $(4,5)$, the immune and inflammatory changes $(6,7)$, the oxidative stress $(8-11)$. The protein $\mathrm{S} 100 \mathrm{~B}$ has gained attention as a potential peripheral biomarker of schizophrenia $(3,12-17)$ and displays neuroprotective or neurodegenerative abilities that depend on its concentrations. At pico- and nanomolar concentrations, S100B promotes cell promotion and differentiation, but induces cellular death at micromolar concentrations (18-20). Elevated levels of S100B in blood have been linked to brain damage (21-24) and a group of psychi- 
atric disorders including schizophrenia, major depressive disorder, bipolar and mood disorder (25-27). Most of these studies were based on the sample of serum, plasma, or cerebrospinal fluid in comparison with healthy controls $(16,28-30)$. Studies have indicated that dysfunction of glial cells, a decreased brain density of glial cells, and alterations in genes associated with astrocytes and oligodendrocytes might present a pathogenic factor in schizophrenia $(15,31)$. However, there is still a lack of consistent association of the levels of S100B with schizophrenia(32) or no association(33). Our recent study has shown that levels of S100B were elevated in the patients of firstepisode drug-naive or acute-stage drug-free with schizophrenia in comparison with healthy controls (34).

The elevation of S100B may involve the inflammatory hypothesis of schizophrenia pathogenesis $(13,35,36)$. Activated glial cells release a variety of pro-inflammatory mediators (e.g., cytokines) which can potentially contribute to neuronal dysfunction and result in the progression of the CNS pathology (37). In addition, S100B, expressed by subsets of $\mathrm{CD}^{+}{ }^{+} \mathrm{CD} 8+\mathrm{T}$ cells and natural killer (NK) cells, is suspected associated with the immune hypothesis of schizophrenia(13). Evidence has indicated that the level of S100B secretion is increased by pro-inflammatory cytokines in C6 glioma of cells and hippocampal slices of rats through the mitogen-activated protein kinase (MAPK) pathways; and the antipsychotic drugs such as haloperidol and risperidone can inhibit the secretion of S100B that is induced by interleukin (IL)-6 stimulation, in which oxidative stress is believed as a component (38).

Free radicals leading to elevated oxidative stress have similar property compared with S100B. Free radicals are species usually produced during cellular metabolism in aerobic cells. In the conditions of increase in production or decrease in scavenging of free radicals, an excessive free radical production can injure neurons in schizophrenia and affect their functions such as membrane transport, impairment of energy production in mitochondria, changes in membrane phospholipid composition, alteration of receptors and transporters as well as neurotransmission (39), which may be involved in the pathophysiology of patients with schizophrenia.

A few studies have investigated the correlation between the protein S100B and oxidative stress. Protein S100B is shown to suppress oxidative cell damage; whereas oxidative stress impairs the ability of S100 proteins to bind and activate protein phosphatase 5 (PP5), a serine/threonine phosphatase involved in oxidative stress responses (40). Studies have shown that a long-term exposure to high blood glucose concentrations leads to an increase in the TOS in the patients with diabetic ketoacidosis and that the neurotransmitter changes in response to this exposure lead to an increase in the levels of S100B (41). It is also found that copy number variations on chromosome 21 disrupted gene human serum albumin (HSA) 21 associated S100B contributes to oxidative stress and apoptosis in Down syndrome human neural progenitors (42) and the role of S100B in the development of cerebral vasospasm and brain damage may result from the induction of oxida- tive stress and neuroinflammation after subarachnoid hemorrhage (43). In investigating the serum levels of multiple oxidative stress biomarkers and S100B in patients with major depressive disorder (MDD) in an acute phase, only serum superoxide dismutase (SOD) and catalase (CAT) activities were found significantly higher compared with healthy subjects; the Hamilton Depression Scale (HAMD) scores have been positively associated with the levels of S100B (44).

In this study, we aimed to investigate the relationship between the level of protein S100B and oxidative stress status in first-episode naive drug patients with schizophrenia, which allows us to minimize the potential impact of confounding factors such as illness duration, medication effects, and the psychiatric and medical co-morbidities. We used malondialdehyde (MDA) and total oxidant status (TOS) in serum to measure the levels of oxidants. MDA is one of the end products of this self-perpetuating lipid peroxidation reaction, which is considered a specific and sensitive measure of lipid auto-oxidation(45); the level of TOS reflects the total effect of all oxidants existing in plasma or serum and body fluids(46).

\section{METHHODS}

\section{Participants}

Participants were recruited from Beijing Huilongguan Hospital, a Beijing-city owned and one of the largest psychiatric hospitals in China. Inpatients, who met the Diagnostic and Statistical Manual of Mental Disorders-IV (DSM-IV) criteria for schizophrenia (American Psychiatric Association, 1994) with an agreement of two senior psychiatrists using the Structured Clinical Interview for DSMIV (SCID), were recruited. It has also been suggested that some antipsychotics, primarily typical antipsychotics may have pro-oxidant effects and increase the oxidative stress and oxidative cell injury(47). Kropp et al. reported that three weeks of treatment with typical antipsychotics might increase the plasma MDA levels compared with the atypical antipsychotics (48). To avoid potential confoundding, two groups of patients were recruited. One group of patients were first-episode and had never taken antipsychotics (first-episode drug-naive); the other group of patients were acute stage and had not taken antipsychotics for at least three weeks prior to the study (drug-free acute stage). Healthy subjects without current or past psychiatric disorders and matched on age and gender were selected from the local community, and Axis I psychiatric disorders was ruled out through psychiatric review evaluation by a psychiatrist.

A complete medical history and physical examination, laboratory tests including a urine and blood screen, and electrocardiogram were obtained from all participants, in order to rule out any neurological or other medical diseases. Neither the patients nor the control subjects had a diagnosis of alcohol or illicit drug abuse/dependence. Excluded criteria: 1) subjects who had another psychiatric disorder or drug and alcohol abuse or dependence, 2) subjects who was incapable of completing the investigation for any reason such as non-cooperation, and mental 
retardation, and 3) subjects who have a family history of diabetes or eating disorders either.

The ethics committee of Beijing Huilongguan Hospital approved the study (Number: 2015-012). After a complete description to all participants, the written informed consent was obtained.

\section{Clinical evaluation}

Information on general socio-demographics and clinical and psychological conditions were collected for each patient or subject with structured forms. Additional information was collected from available medical records or with assistance from a family member or relative and treating clinician. The patient's psychopathological symptoms were assessed using the Positive and Negative Syndrome Scale (PANSS) on the day of the blood draw, which was conducted independently by two psychiatrists. To ensure consistency and reliability of ratings across the study, two psychiatrists had simultaneously attended a training session in the use of the PANSS before this study started. After necessary training, an intra-rater correlation coefficient higher than 0.8 was required for the evaluation of PANSS total score. Brief psychiatric rating scale (BPRS) and the measurement and treatment research to improve cognition in schizophrenia (MATRICS) and Matrics Consensus Cognitive Battery (MCCB) were also assessed and collected for each patient at baseline as part of other studies. The concentration of MDA was measured in terms of nmol/gmHb. The levels of TOS was determined using a colorimetric method developed by Erel(46). The assay is based on the oxidation of ferrous ion to ferric ion in the presence of various oxidant species in acidic medium and the measurement of the ferric ion by xylenol orange. The assay is calibrated with hydrogen peroxide, and the results are measured in term of $\mu \mathrm{mol} \mathrm{H} 202$ Equiv. /L.

\section{Blood samples and Assays}

Serum samples from all subjects were collected at $7 \mathrm{AM}$ following overnight fasting for laboratory tests. $5 \mathrm{ml}$ of the venous blood sample was taken from the antecubital vein of each participant. The blood sample in lithium heparin tube was centrifuged $\left(4^{\circ} \mathrm{C}, 3500 \mathrm{rpm}, 10 \mathrm{~min}\right)$, aliquoted, and then stored at $-70^{\circ} \mathrm{C}$ until assayed. The same technician, who was blind to the clinical data, assayed all samples. The identity of all subjects was coded and maintained by the investigator until when all biochemical analyses were completed. Inter- and intra-assay variation coefficients were $7 \%$ and $5 \%$, respectively.

Serum levels of S100B were measured within one week by the sandwich enzyme-linked immune sorbent assay (ELISA) using a commercially available kit (Ad Litteram Diagnostic Laboratories, Inc., San Diego, CA, USA). The detailed information has been described elsewhere (34). The levels of MDA were measured using monitoring thiobarbituric acid-reactive substances (TBARs) assay kit (Cayman Chemical Company, Ann Arbor, MI, USA). The principle of the assay, based on the procedure of Dawn-linsley (49).

\section{Statistical analysis}

SPSS, Statistical Package for Social Sciences, for Windows 17.0 and R 3.2.0 Package (https://www.r-project.org/) were used for the statistical analysis. General linear regression analysis was performed to examine the association of S100B with the levels of oxidative stress as measured by TOS and MDA. The analysis was first performed using all participants together, with schizophrenia patients with the first episode drug-naive and acute phase drug-free patients with schizophrenia, and healthy controls, by fitting a group by levels of S100B interaction term while adjusting for age and sex, followed by a stratification analysis by the group. We then performed an analysis of patients only to maximize the statistical power and adjusting for age of onset (years), duration of illness, smoker status, and years of education. A threshold level of 0.05 was used for declaring statistically significant.

\section{RESULTS}

Table 1 presents the demographics and descriptive statistics of all measurement and patient characteristics including psychopathological symptom and cognitive measures. In total, the study included 29 schizophrenia patients with the first-episode drug-naive (Mean age=27.62; $\mathrm{SD}=7.18$ years), 29 patients with the drug-free acute stage (Mean age $=27.03, \mathrm{SD}=7.68$ years), and 50 healthy controls (Mean age $=25.92, \mathrm{SD}=6.69$ years). There was no significant difference in mean age and distribution of sex among three groups $(p>0.05)$. We noted significant differences in the levels of S100B, TOS, and cognitive functions as measured by MCCB composite score $(p<0.01)$, but no significant difference in the levels of MDA ( $p>0.05)$ were found among the three study groups.

While no significant difference in the levels of protein S100B, TOS and MCCB composite score between the two groups of patients (i.e., drug-naive and drug-free patients), there were significant differences in these measures between patients and healthy control (Table 1). We noted a difference in psycho-pathological symptoms of PANSS Positive score and general psychopathology $(p<0.05)$ between two patient groups. The first-episode drug-naive patients appear more severe in symptoms. Specifically, the schizophrenia patients of first-episode drug-naive had a higher PANSS positive score (Mean, 25.10; SD, 5.07) than the drug-free acute stage patients (Mean, 22.12; SD, 6.79), and a higher PANSS total score (Mean, 89.36; SD, 15.11) than drug-free group (Mean, 82.35; SD, 14.97).

In analysis of all groups together adjusting for age and sex, we found that levels of protein S100B were associated with the concentration of both TOS (Beta $=15.45 ; p=0.0050)$ and MDA (Beta=7.33; $p=0.0066$ ) in the first episode drug-naive patients with schizophrenia (Table 2). However, there was no association of TOS (Beta=11.256; $p=0.0789$ ) nor MDA (Beta=-2.819; $p=0.3578$ ) with protein $\mathrm{S} 100 \mathrm{~B}$ in the drugfree acute phase patients with schizophrenia; no significant association of either TOS ( $p=0.7458)$ or MDA ( $p=0.651)$ with S100B in the healthy controls. We noted a significant interaction between the participant group and TOS ( $p=0.0014)$ and between participant group and MDA ( $p=0.0159)$ on the levels of S100B in serum, suggesting that the association of serum oxidants and S100B was different between patients and healthy controls. 
Table 1. Demographics and descriptive statistics of serum biological markers and characteristics of the participants

\begin{tabular}{|c|c|c|c|c|c|c|c|c|c|c|c|c|c|c|}
\hline & \multicolumn{4}{|c|}{ First episode drug-naive } & \multicolumn{4}{|c|}{ Drug-free acute stage } & \multicolumn{6}{|c|}{ Healthy control } \\
\hline & $\mathrm{N}$ & Mean & Median & SD & $\mathrm{N}$ & Mean & Median & SD & Sig* & $\overline{\mathrm{N}}$ & Mean & Median & SD & Sig** \\
\hline Age (year) & 39 & 27.62 & 27.00 & 7.18 & 34 & 27.03 & 26.00 & 7.68 & n.s. & 50 & 25.92 & 24.00 & 6.69 & n.s. \\
\hline Sex & 39 & 0.59 & & & 34 & 0.59 & & & n.s. & 50 & 0.48 & 0.00 & 0.50 & n.s. \\
\hline $\mathrm{S} 100 \mathrm{~B} 1(\mu \mathrm{g} / \mathrm{L})$ & 29 & 234.91 & 239.06 & 79.33 & 29 & 210.15 & 202.97 & 72.53 & n.s. & 50 & 117.72 & 108.50 & 46.91 & ** \\
\hline Total oxidant capacity $(\mu \mathrm{mol} / \mathrm{L})$ & 29 & 8.83 & 7.69 & 2.89 & 29 & 10.08 & 9.94 & 2.02 & n.s. & 50 & 15.66 & 15.36 & 4.26 & ** \\
\hline Malondialdehyde (nmol/gmHb) & 29 & 8.35 & 5.74 & 5.69 & 29 & 8.06 & 7.04 & 4.48 & n.s. & 50 & 6.41 & 4.34 & 4.11 & n.s. \\
\hline PANSS score & & & & & & & & & & & & & & \\
\hline $\begin{array}{l}\text { Positive } \\
\text { Pat }\end{array}$ & 39 & 25.10 & 24.00 & 5.07 & 34 & 22.12 & 21.50 & 6.79 & * & & & & & \\
\hline Negative & 39 & 21.95 & 22.00 & 6.39 & 34 & 23.38 & 21.50 & 6.54 & n.s. & & & & & \\
\hline General & 39 & 42.31 & 40.00 & 8.02 & 34 & 36.85 & 35.50 & 7.41 & * & & & & & \\
\hline PANSS total score & 39 & 89.36 & 87.00 & 15.11 & 34 & 82.35 & 81.50 & 14.97 & n.s & & & & & \\
\hline Brief psychiatric rating score & 29 & 47.69 & 46.00 & 7.12 & 29 & 42.76 & 43.00 & 7.64 & * & & & & & \\
\hline Smoker (\%) & 29 & 6.90 & & & 29 & 37.93 & & & * & & & & & \\
\hline Education (year) & 29 & 12.65 & 12.00 & 2.92 & 29 & 12.48 & 12.00 & 2.31 & n.s. & & & & & \\
\hline Age at onset (year) & 39 & 24.94 & 24.00 & 6.54 & 34 & 23.42 & 23.12 & 5.89 & n.s. & & & & & \\
\hline Total duration of illness(month) & 39 & 31.15 & 20.00 & 33.83 & 34 & 46.29 & 34.00 & 47.14 & n.s. & & & & & \\
\hline MCCB composite score & 35 & 44.74 & 45.00 & 11.19 & 27 & 45.07 & 44.00 & 11.08 & n.s. & 50 & 54.90 & 56.50 & 8.35 & $* *$ \\
\hline
\end{tabular}

$44.74 \quad 45.00 \quad 11.19$

45.07

${ }^{*}, \mathrm{p}<0.05$, a significant difference between first episode drug-naive and drug-free acute stage of patients with schizophrenia

**, $\mathrm{p}<0.01$, a significant difference among three groups; n.s., non-significance ( $\mathrm{p}>0.05)$;

Sig*, significance between first-episode drug naive and Drug-free acute stage;

Sig**, significance between all cases and healthy controls 
Table 2. Regression analysis of oxidative stress with levels of S100B in the serum of patients with Schizophrenia

\begin{tabular}{rrrrrrrrr}
\hline & Group & $\mathrm{N}$ & Beta & SE & t Value & $P$ & $R^{2}(\%)$ & $P_{\text {int }}$ \\
\hline \multirow{3}{*}{ TOS } & Control & 50 & -0.524 & 1.606 & -0.33 & 0.7458 & 0.22 & 0.0014 \\
& Drug-naive & 29 & 15.445 & 5.015 & 3.08 & 0.0050 & 25.28 \\
& Drug-free & 29 & 11.256 & 6.143 & 1.83 & 0.0789 & 9.75 \\
& & & & & & & \\
\multirow{3}{*}{ MDA } & Control & 50 & 0.766 & 1.682 & 0.46 & 0.6510 & 0.43 & 0.0159 \\
& Drug-naive & 29 & 7.330 & 2.476 & 2.96 & 0.0066 & 23.86 \\
& Drug-free & 29 & -2.819 & 3.009 & -0.94 & 0.3578 & 2.79 & \\
\hline
\end{tabular}

$P_{\text {int }}$, the $\mathrm{p}$ value for the interaction between the group and oxidative stress; Analysis was performed by stratifying group while adjusting for age, sex and participant group.

In the patient specific-analysis, we found that the levels of S100B were associated with TOS $\left(R^{2}=25.28 \%\right.$; Figure $\left.1, \mathrm{~A} 1\right)$ and MDA $\left(R^{2}=23.86 \%\right.$; Figure $\left.1, \mathrm{~A} 2\right)$ in the first-episode drug-naive patients. While the TOS was not associated with the levels of serum protein S100B in the drug-free acute phase patients with schizophrenia $\left(p=0.0789 ; R^{2}=\right.$ 0.0975; Figure 1, B1), we noted a clear linear trend in the small size of sample $(n=29)$. However, we find no trend of association of S100B with MDA (Figure 1, B2).

\section{A1. Drug naive patients}

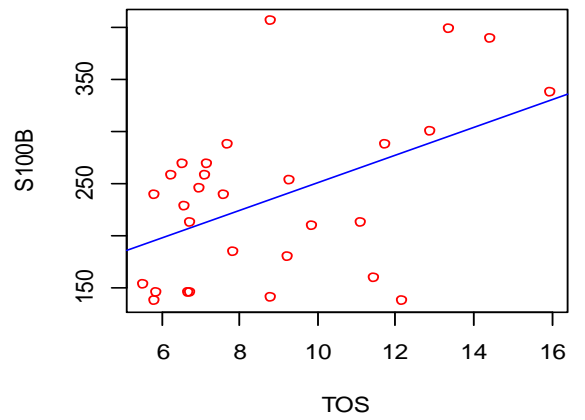

B1. Drug free acute phase patients

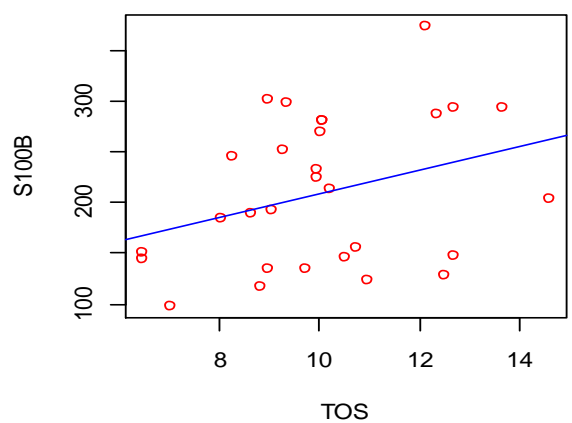

A2. Drug naive patients

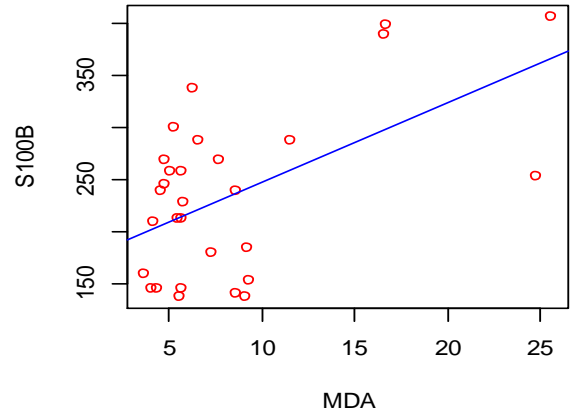

B2. Drug free acute phase patients

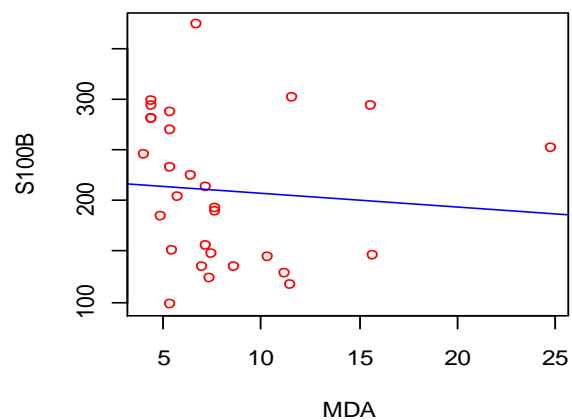

Figure 1. The best-fitted lines from the simple linear regression analysis of oxidants and levels of S100B in patients with schizophrenia (A1. TOS in the first-episode drug-naive; A2. MDA in the drug-free acute stage; B1. TOS in the first-episode drug-naive; B2. MDA in the drug-free acute stage).

To control for potential confounding factors in patients characteristics such as smoke status, duration of illness and educations, we further confirmed the association of oxidants and levels of S100B in the patient-only analysis (Table 3). The associations of TOS with S100B became slightly more significant in both groups of the first-episode drug-naive $(p=0.0038)$ and drug-free acute phase $(p=0.0670)$. In the combined patient groups, TOS was more significantly associated with S100B ( $p=0.0026)$, and there was no interaction between TOS and patient group 
$(p=0.4390)$. However, we did not find any change in the association of MDA in either of patient groups. It is interesting to note that in the patient combined, MDA was still associated with S100B $(p=0.0480)$, but we noted a significant interaction between the patient group and MDA on the levels of S100B, which had been noted in the scatter plot (Figure 1, A2 vs. B2)

To further determine which oxidant measures were associated with $\mathrm{S} 100 \mathrm{~B}$, we performed multiple regression analysis of two markers in the same regression model
(Table 3). In the first episode drug-naive patients, both TOS (Beta=12.88; $p=0.0103$ ) and MDA (Beta $=6.46$; $p=0.0167$ ) were significantly associated with S100B. However, two markers were no longer significantly associated with S100B in the drug-free acute phase patients, although TOS showed a strong effect size (Beta=10.95; $p=0.1116$ ) on the levels of S100B. Combined together two groups of patients, only TOS was associated with S100B (Beta=12.83; $p=0.0015)$, but not MDA (Beta= 2.52; $p=0.1827$ ).

Table 3. Multiple regression analysis of oxidants (TOS and MDA) and levels of serum S100B in patients with schizophrenia after further adjusting for potential confounding such as smoke status, duration of illness and years of educations.

\begin{tabular}{|c|c|c|c|c|c|c|}
\hline & Group & Parameter & Beta & SE & t-Value & $\mathbf{p}$ \\
\hline \multicolumn{7}{|l|}{ Simple regression } \\
\hline & First-episode & TOS & 15.77 & 4.87 & 3.24 & 0.0038 \\
\hline & Drug-free & TOS & 12.71 & 6.59 & 1.93 & 0.0670 \\
\hline & Combined & TOS & 12.42 & 3.91 & 3.17 & 0.0026 \\
\hline & Interaction & TOS*Patient group & 6.33 & 8.11 & 0.78 & 0.4390 \\
\hline \multicolumn{7}{|l|}{ Simple regression } \\
\hline & First-episode & MDA & 7.90 & 2.65 & 2.99 & 0.0068 \\
\hline & Drug-free & MDA & -2.98 & 3.37 & -0.89 & 0.3857 \\
\hline & Combined & MDA & 4.11 & 2.03 & 2.03 & 0.0480 \\
\hline & Interaction & MDA*Patient group & 8.86 & 4.20 & 2.11 & 0.0400 \\
\hline \multicolumn{7}{|l|}{ Multiple regression } \\
\hline & First-episode & MDA & 6.46 & 2.47 & 2.61 & 0.0167 \\
\hline & & TOS & 12.88 & 4.55 & 2.83 & 0.0103 \\
\hline & Drug-free & MDA & -2.29 & 3.16 & -0.72 & 0.4778 \\
\hline & & TOS & 10.95 & 6.58 & 1.66 & 0.1116 \\
\hline & Combined & MDA & 2.52 & 1.86 & 1.35 & 0.1827 \\
\hline & & TOS & 12.83 & 3.82 & 3.36 & 0.0015 \\
\hline
\end{tabular}

\section{DISCUSSION}

In the present study, we found that the levels of oxidants measured by TOS and MDA in serum were associated with the elevated levels of serum protein S100B in patients with schizophrenia. The associations of S100B with both TOS and MDA were consistent in the first-episode drug-naive patients with schizophrenia, but no significant association in drug-free acute stage patients. We did not find that any significant association of oxidants with protein S100B in healthy controls.

Our findings that association of oxidants with the levels of protein S100B is consistent with the previous study (50). One speculation is that a higher level of oxidants causes an increase in the levels of serum protein S100B. The reactive oxygen species (ROS) overproduction in myoblasts has been shown to cause an upregulation of protein S100B via nuclear factor kappa-light-chain-enhancer of activated $\mathrm{B}$ cells (NF-kappaB) activation (51). In the high concentrations of oxidants, excessive reactive oxygen species (ROS) cause the damage on the components of the cells, including the proteins (enzymes, receptors), the lipids and deoxyribonucleic acid (DNA), which may consequently affect the apoptosis and the cell death(52-55). Oxidative stress is not only responsible for the neuron apoptosis but also can provoke the astroglial cell death. In the meantime, pituitary adenylate cyclase-activating poly-peptide (PACAP), a substance that can promote neuron survival, exerts a potent protective effect against the oxidative stress-induced astrocyte death. The anti-apoptotic activity of PACAP on the astrocytes is mediated through the protein kinase A, PKC and MAPK transduction pathways, by the inhibition of the ROS-induced mitochondrial dysfunctions and caspase 3 activations. Therefore, the oxidative stress has toxic effects on the astroglial cells and then affects the synthesis and the secretion of S100B (56).

Conversely, the elevated level of protein S100B leads to an increase in oxidant levels. In the Down syndrome neural progenitor cells, constitutively over-expression of S100B leads to an increase in reactive oxygen species (ROS) formation and activation of stress response kinases(57). S100B stimulates inducible nitric oxide synthase in rat primary cortical astrocytes through a signal transduction pathway that involves activation of the transcription factor NF-kappaB (58). Furthermore, S100B-induced inducible 
nitric oxide synthase promoter activation was inhibited upon the mutation of the NF-kappaB response element in the promoter, whereas transfection of cells with an NFkappaB inhibitor blocked the S100B-induced inducible nitric oxide synthase promoter activation and nitric oxide production. These studies define a signal transduction pathway by which S100B activation of glia could participate in the generation of oxidative stress in the brain. The astroglial cells are, the most important source of the free radicals in the CNS (59) and S100B was primarily expressed in astrocytes. High glucose environments enhanced the pentose phosphate pathway (PPP) in the astroglia, reducing the ROS production and thereby play a neuroprotective role (60). Activated astroglial cells produce large amounts of nitric oxide (NO) which, through the binding to the soluble guanylyl cyclase, rapidly increases the cyclic guanosinc monophosphate (GMP) concentrations. The stimulation of these glucose-metabolizing pathways by NO would represent a transient attempt by the glial cells to compensate for the energy impairment and the oxidative stress, and thus to emerge from an otherwise pathological outcome (61). These point out that the increased S100B may be a source of the oxidative stress or a compensatory response to the oxidative stress.

It is also likely that there is no direct interaction between the oxidative stress and the S100B and both may be associated with the neurodegenerative process (62). Studies have indicated a neurodegenerative component in schizophrenia $(63,64)$; and the accelerated aging in schizophrenia was supported by the structural and the functional brain abnormalities, the higher incidence of the aging-associated metabolic profiles and disease(65), the early cognitive decline, and the altered telomere dynamics(66). In addition, the oxidative stress and the mitochondrial dysfunction play essential roles in the pathogenesis of the neurodegenerative disorders(67) may also support the "accelerated aging" in schizophrenia. On the other hand, in an S100B over-expressing mouse model of pathological aging, the antioxidant vitamin $\mathrm{E}$ is shown to increase S100B-mediated microglial activation (68). There is inconsistent evidence that dietary compounds (such as trans-resveratrol) can inhibit or reverse oxidative stress, and the reduction of $\mathrm{S} 100 \mathrm{~B}$ secretion induced by $\mathrm{H}_{2} \mathrm{O}_{2}$ was not changed by resveratrol (69). In cirrhosis repre-sents, a negative correlation between S100B and oxidative stress measured by the thiobarbituric acid method in the case group was found (70). The inconsistent results were interpreted by the difference in the assay methods on oxidative stress.

In summary, we observed that the levels of the serum protein S100B was associated with the concentration of both TOS and MDA in the first episode drug-naive group and the association of protein S100B with TOS was weaker and no association with MDA in the drug-free group.

\section{Limitations}

Our results should be read with care. This was only based on the baseline measures of S100B and TOS or MDA. We only analyzed two measures of oxidant levels: TOS and MDA but did not measure the antioxidant levels, the imbalance of antioxidants and oxidants determine the level of oxidative stress. In addition, our sample size is still limited in both inpatient groups and healthy controls, and we did not collect detailed information on smoking history except for the current smoke status, other medications, etc. To gain statistical power and test the possible causal relationship, a therapeutic study would help validate these findings.

\section{CONCLUSION}

Our study indicates that the high level of oxidants is associated with an elevated level of protein S100B. This warrants a further study for validation of this association and examines the potential causal relationship.

\section{CONFILICT OF INTERESTS}

We declare that there is no conflict of interest regarding the publication of this paper.

\section{ACKNOWLWDGEMENTS}

This work was supported by the National Natural Science Foundation of China (81761128201), and by Dengfeng plan of Beijing Municipal Administration of Hospitals (DFL20151901). The authors are grateful to Jia Li and YueChan Wang for their technical assistance. Appreciation is also owned to the patients, clinical psychiatrists and nursing staff of the Wards 1, 2, 3 and 5 in Beijing Huilongguan Hospital for their participation and collaboration.

\section{REFERENCES}

1. Tramontina F, Conte S, Goncalves D, Gottfried C, Portela LV, Vinade L, et al. Developmental changes in S100B content in brain tissue, cerebrospinal fluid, and astrocyte cultures of rats. Cell Mol Neurobiol. 2002;22(3):373-8.

2. Koh SX, Lee JK. S100B as a marker for brain damage and blood-brain barrier disruption following exercise. Sports Med. 2014;44(3):369-85.

3. Rothermundt M, Ahn JN, Jorgens S. S100B in schizophrenia: an update. Gen Physiol Biophys. 2009;28 Spec No Focus:F7681.

4. Hori H, Yoshimura R, Katsuki A, Atake K, Nakamura J. Relationships between brain-derived neurotrophic factor, clinical symptoms, and decision-making in chronic schizophrenia: data from the Iowa Gambling Task. Frontiers in behavioral neuroscience. 2014;8:417.

5. Koeva YA, Sivkov ST, Akabaliev VH, Ivanova RY, Deneva TI, Grozlekova LS, et al. Brain-derived neurotrophic factor and its serum levels in schizophrenic patients. Folia medica. 2014;56(1):20-3.

6. Song X, Fan X, Zhang J, Zheng H, Li X, Pang L, et al. Prolactin serum levels correlate with inflammatory status in drugnaive first-episode schizophrenia. The world journal of biological psychiatry: the official journal of the World Federation of Societies of Biological Psychiatry. 2014; 15(7): 546-52.

7. Xiu MH, Yang GG, Tan YL, Chen da C, Tan SP, Wang ZR, et al. Decreased interleukin-10 serum levels in first-episode drugnaive schizophrenia: relationship to psychopathology. Schizophrenia research. 2014;156(1):9-14. 
8. Okusaga 00. Accelerated aging in schizophrenia patients: the potential role of oxidative stress. Aging Dis. 2014;5(4):25662.

9. Emiliani FE, Sedlak TW, Sawa A. Oxidative stress and schizophrenia: recent breakthroughs from an old story. Current opinion in psychiatry. 2014;27(3):185-90.

10. Flatow J, Buckley P, Miller BJ. Meta-analysis of oxidative stress in schizophrenia. Biol Psychiatry. 2013;74(6):400-9.

11. Albayrak Y, Unsal C, Beyazyuz M, Unal A, Kuloglu M. Reduced total antioxidant level and increased oxidative stress in patients with deficit schizophrenia: a preliminary study. Prog Neuropsychopharmacol Biol Psychiatry. 2013;45:144-9.

12. Yelmo-Cruz S, Morera-Fumero AL, Abreu-Gonzalez P. S100B and schizophrenia. Psychiatry Clin Neurosci. 2013;67(2):6775.

13. Steiner J, Walter M, Wunderlich MT, Bernstein HG, Panteli B, Brauner M, et al. A new pathophysiological aspect of S100B in schizophrenia: potential regulation of $\mathrm{S} 100 \mathrm{~B}$ by its scavenger soluble RAGE. Biol Psychiatry. 2009;65(12):110710 .

14. Steiner J, Bielau H, Bernstein HG, Bogerts B, Wunderlich MT. Increased cerebrospinal fluid and serum levels of S100B in first-onset schizophrenia are not related to a degenerative release of glial fibrillar acidic protein, myelin basic protein and neurone-specific enolase from glia or neurones. J Neurol Neurosurg Psychiatry. 2006;77(11):1284-7.

15. Rothermundt M, Falkai P, Ponath G, Abel S, Burkle H, Diedrich $\mathrm{M}$, et al. Glial cell dysfunction in schizophrenia indicated by increased S100B in the CSF. Mol Psychiatry. 2004;9(10):897-9.

16. Lara DR, Gama CS, Belmonte-de-Abreu P, Portela LV, Goncalves CA, Fonseca M, et al. Increased serum S100B protein in schizophrenia: a study in medication-free patients. J Psychiatr Res. 2001;35(1):11-4.

17. Aleksovska K, Leoncini E, Bonassi S, Cesario A, Boccia S, Frustaci A. Systematic review and meta-analysis of circulating S100B blood levels in schizophrenia. PLoS One. 2014;9(9):e106342.

18. Kleindienst A, Hesse F, Bullock MR, Buchfelder M. The neurotrophic protein S100B: value as a marker of brain damage and possible therapeutic implications. Prog Brain Res. 2007;161:317-25.

19. Sorci G, Riuzzi F, Arcuri C, Tubaro C, Bianchi R, Giambanco I, et al. S100B protein in tissue development, repair and regeneration. World J Biol Chem. 2013;4(1):1-12.

20. Businaro R, Leone S, Fabrizi C, Sorci G, Donato R, Lauro GM, et al. S100B protects LAN-5 neuroblastoma cells against Abeta amyloid-induced neurotoxicity via RAGE engagement at low doses but increases Abeta amyloid neurotoxicity at high doses. J Neurosci Res. 2006;83(5):897-906.

21. Egea-Guerrero JJ, Murillo-Cabezas F, Gordillo-Escobar E, Rodriguez-Rodriguez A, Enamorado-Enamorado J, RevueltoRey J, et al. S100B protein may detect brain death development after severe traumatic brain injury. J Neurotrauma. 2013;30(20):1762-9.

22. Astrand R, Unden J, Romner B. [High time to start using the brain injury marker S100B when diagnosing minor head injuries]. Lakartidningen. 2013;110(38):1675.

23. Lesko MM, O'Brien SJ, Childs C, Bouamra 0, Rainey T, Lecky F. Comparison of several prognostic tools in traumatic brain injury including S100B. Brain Inj. 2014;28(7):987-94.

24. Heidari K, Asadollahi S, Jamshidian M, Abrishamchi SN, Nouroozi M. Prediction of neuropsychological outcome after mild traumatic brain injury using clinical parameters, serum S100B protein and findings on computed tomography. Brain Inj. 2015;29(1):33-40.

25. Manev H, Manev R. S100B: an old neurotrophic factor with putative new roles in psychiatric illnesses. J Psychiatr Res. 2001;35(6):347-50.
26. Schroeter ML, Steiner J. Elevated serum levels of the glial marker protein S100B are not specific for schizophrenia or mood disorders. Mol Psychiatry. 2009;14(3):235-7.

27. Andreazza AC, Cassini C, Rosa AR, Leite MC, de Almeida LM, Nardin P, et al. Serum S100B and antioxidant enzymes in bipolar patients. J Psychiatr Res. 2007;41(6):523-9.

28. Schroeter ML, Abdul-Khaliq H, Fruhauf S, Hohne R, Schick G, Diefenbacher A, et al. Serum S100B is increased during early treatment with antipsychotics and in deficit schizophrenia. Schizophr Res. 2003;62(3):231-6.

29. Rothermundt M, Ponath G, Glaser T, Hetzel G, Arolt V. S100B serum levels and long-term improvement of negative symptoms in patients with schizophrenia. Neuropsychopharmacology. 2004;29(5):1004-11.

30. O'Connell K, Thakore J, Dev KK. Levels of S100B are raised in female patients with schizophrenia. BMC Psychiatry. 2013; 13:146.

31. Katsel P, Davis KL, Li C, Tan W, Greenstein E, Kleiner Hoffman LB, et al. Abnormal indices of cell cycle activity in schizophrenia and their potential association with oligodendrocytes. Neuropsychopharmacology : official publication of the American College of Neuropsycho-pharmacology. 2008; 33(12):2993-3009.

32. Gattaz WF, Lara DR, Elkis H, Portela LV, Goncalves CA, Tort $\mathrm{AB}$, et al. Decreased S100-beta protein in schizophrenia: preliminary evidence. Schizophrenia research. 2000;43(23):91-5.

33. van de Kerkhof NW, Fekkes D, van der Heijden FM, Verhoeven WM. BDNF and S100B in psychotic disorders: evidence for an association with treatment responsiveness. Acta Neuropsychiatr. 2014;26(4):223-9.

34. Chen S, Tian L, Chen N, Xiu M, Wang Z, Yang G, et al. Cognitive dysfunction correlates with elevated serum S100B concentration in drug-free acutely relapsed patients with schizophrenia. Psychiatry Res. 2017;247:6-11.

35. Mondelli V, Howes O. Inflammation: its role in schizophrenia and the potential anti-inflammatory effects of antipsychotics. Psychopharmacology. 2014;231(2):317-8.

36. Anderson G, Berk M, Dodd S, Bechter K, Altamura AC, Dell'osso B, et al. Immuno-inflammatory, oxidative and nitrosative stress, and neuroprogressive pathways in the etiology, course and treatment of schizophrenia. Prog Neuropsychopharmacol Biol Psychiatry. 2013;42:1-4.

37. Khansari N, Shakiba Y, Mahmoudi M. Chronic inflammation and oxidative stress as a major cause of age-related diseases and cancer. Recent patents on inflammation \& allergy drug discovery. 2009;3(1):73-80.

38. de Souza DF, Wartchow K, Hansen F, Lunardi P, Guerra MC, Nardin P, et al. Interleukin-6-induced S100B secretion is inhibited by haloperidol and risperidone. Prog Neuropsychopharmacol Biol Psychiatry. 2013;43:14-22.

39. Dietrich-Muszalska A, Kontek B. Lipid peroxidation in patients with schizophrenia. Psychiatry Clin Neurosci. 2010; 64(5):469-75.

40. Yamaguchi F, Tsuchiya M, Shimamoto S, Fujimoto T, Tokumitsu H, Tokuda M, et al. Oxidative Stress Impairs the Stimulatory Effect of S100 Proteins on Protein Phosphatase 5 Activity. Tohoku J Exp Med. 2016;240(1):67-78.

41. Kaya C, Atas A, Aksoy N, Kaya EC, Abuhandan M. Evaluation of Pre-Treatment and Post-Treatment S100B, Oxidant and Antioxidant Capacity in Children with Diabetic Ketoacidosis. J Clin Res Pediatr Endocrinol. 2015;7(2):109-13.

42. Lu J, Esposito G, Scuderi C, Steardo L, Delli-Bovi LC, Hecht JL, et al. S100B and APP promote a gliocentric shift and impaired neurogenesis in Down syndrome neural progeni-tors. PLoS One. 2011;6(7):e22126.

43. Chong ZZ. S100B raises the alert in subarachnoid hemorrhage. Rev Neurosci. 2016;27(7):745-59. 
44. Tsai MC, Huang TL. Increased activities of both superoxide dismutase and catalase were indicators of acute depressive episodes in patients with major depressive disorder. Psychiatry Res. 2016;235:38-42.

45. Dadheech G, Mishra S, Gautam S, Sharma P. Evaluation of antioxidant deficit in schizophrenia. Indian J Psychiatry. 2008;50(1):16-20.

46. Erel 0. A new automated colorimetric method for measuring total oxidant status. Clinical biochemistry. 2005;38 (12): 1103-11.

47. Cadet JL, Lohr JB. Possible involvement of free radicals in neuroleptic-induced movement disorders. Evidence from treatment of tardive dyskinesia with vitamin E. Ann N Y Acad Sci. 1989;570:176-85.

48. Kropp S, Kern V, Lange K, Degner D, Hajak G, Kornhuber J, et al. Oxidative stress during treatment with first- and secondgeneration antipsychotics. J Neuropsychiatry Clin Neurosci. 2005;17(2):227-31.

49. Dawn-Linsley M, Ekinci FJ, Ortiz D, Rogers E, Shea TB. Monitoring thiobarbituric acid-reactive substances (TBARs) as an assay for oxidative damage in neuronal cultures and central nervous system. Journal of neuroscience methods. 2005;141 (2):219-22.

50. Sarandol A, Kirli S, Akkaya C, Altin A, Demirci M, Sarandol E. Oxidative-antioxidative systems and their relation with serum S100 B levels in patients with schizophrenia: effects of short term antipsychotic treatment. Prog Neuropsychopharmacol Biol Psychiatry. 2007;31(6):1164-9.

51. Morozzi G, Beccafico S, Bianchi R, Riuzzi F, Bellezza I, Giambanco I, et al. Oxidative stress-induced S100B accumulation converts myoblasts into brown adipocytes via an NFkappaB/YY1/miR-133 axis and NF-kappaB/YY1 /BMP-7 axis. Cell Death Differ. 2017;24(12):2077-88.

52. Maes M, Galecki P, Chang YS, Berk M. A review on the oxidative and nitrosative stress (O\&NS) pathways in major depression and their possible contribution to the (neuro)degenerative processes in that illness. Progress in neuropsychopharmacology \& biological psychiatry. 2011; 35(3): 676-92.

53. Halliwell B, Lee CY. Using isoprostanes as biomarkers of oxidative stress: some rarely considered issues. Antioxidants \& redox signaling. 2010;13(2):145-56.

54. Halliwell B. Oxidative stress and neurodegeneration: where are we now? Journal of neurochemistry. 2006;97(6):163458.

55. Halliwell B. Free radicals and antioxidants - quo vadis? Trends in pharmacological sciences. 2011;32(3):125-30.

56. Masmoudi-Kouki O, Douiri S, Hamdi Y, Kaddour H, Bahdoudi S, Vaudry D, et al. Pituitary adenylate cyclase-activating polypeptide protects astroglial cells against oxidative stressinduced apoptosis. Journal of neurochemistry. 2011;117 (3):403-11.

57. Esposito G, Imitola J, Lu J, De Filippis D, Scuderi C, Ganesh VS, et al. Genomic and functional profiling of human Down syndrome neural progenitors implicates S100B and aquaporin 4 in cell injury. Hum Mol Genet. 2008;17(3):440-57.
58. Lam AG, Koppal T, Akama KT, Guo L, Craft JM, Samy B, et al. Mechanism of glial activation by S100B: involvement of the transcription factor NFkappaB. Neurobiol Aging. 2001; 22(5):765-72.

59. Lohr JB. Oxygen radicals and neuropsychiatric illness. Some speculations. Archives of general psychiatry. 1991;48(12): 1097-106.

60. Takahashi S. [Astroglial protective mechanisms against ROS under brain ischemia]. Rinsho shinkeigaku = Clinical neurology. 2011;51(11):1032-5.

61. Bolanos JP, Almeida A. Modulation of astroglial energy metabolism by nitric oxide. Antioxidants \& redox signaling. 2006;8(5-6):955-65.

62. Shivakumar V, Kalmady SV, Venkatasubramanian G, Ravi V, Gangadhar BN. Do schizophrenia patients age early? Asian J Psychiatr. 2014;10:3-9.

63. Papanastasiou E, Gaughran F, Smith S. Schizophrenia as segmental progeria. Journal of the Royal Society of Medicine. 2011;104(11):475-84.

64. Kirkpatrick B, Messias E, Harvey PD, Fernandez-Egea E, Bowie CR. Is schizophrenia a syndrome of accelerated aging? Schizophrenia bulletin. 2008;34(6):1024-32.

65. Fernandez-Egea E, Bernardo M, Donner T, Conget I, Parellada E, Justicia A, et al. Metabolic profile of antipsychotic-naive individuals with non-affective psychosis. The British journal of psychiatry : the journal of mental science. 2009;194 (5):434-8.

66. Kao HT, Cawthon RM, Delisi LE, Bertisch HC, Ji F, Gordon D, et al. Rapid telomere erosion in schizophrenia. Molecular psychiatry. 2008;13(2):118-9.

67. Pope S, Land JM, Heales SJ. Oxidative stress and mitochondrial dysfunction in neurodegeneration; cardio-lipin a critical target? Biochimica et biophysica acta. 2008;1777(78):794-9.

68. Bialowas-McGoey LA, Lesicka A, Whitaker-Azmitia PM. Vitamin E increases S100B-mediated microglial activation in an S100B-overexpressing mouse model of pathological aging. Glia. 2008;56(16):1780-90.

69. de Almeida LM, Leite MC, Thomazi AP, Battu C, Nardin P, Tortorelli LS, et al. Resveratrol protects against oxidative injury induced by $\mathrm{H} 2 \mathrm{O} 2$ in acute hippocampal slice preparations from Wistar rats. Arch Biochem Biophys. 2008; 480 (1):27-32.

70. Ribeiro L, Andreazza AC, Salvador M, da Silveira TR, Vieira S, Nora DB, et al. Oxidative stress and S100B protein in cirrhotic children. Neurochem Res. 2007;32(9):1600-3.

Copyright (C) 2019 by the author(s). Licensee Global Clinical and Translational Research Institute. This is an open-access article distributed under the terms and conditions of the Creative Commons Attribution License (CCBY4.0, https://creative-commons.org/licenses/by/ $4.0 /$ ), which permits unrestricted use, distribution, and reproduction in any medium, provided the original work is properly cited.

How to cite this article:

Liu L, Li Y, Bian Y, Yang F, Li X, Han X, Tian L, Chen S, Wang Z, Tan Y. Serum levels of oxidants and protein S100B were associated in the first-episode drug naïve patients with schizophrenia. Glob Clin Transl Res. 2019; 1 (2):84-92.

Copyright (C) 2019 by Global Clinical and Translational Research. 